\title{
Treatment of Children with Autism Spectrum Disorder in Vlora
}

\author{
Ph.D Candidate, Sulltana Bilbili
}

\author{
"Pedagogical Academy of Tirana", Tirana
} tanabilbili@yahoo.com

\section{Doi:10.5901/mjss.2013.v4n6p183}

\begin{abstract}
Autism is a complex lifelong developmental disability that causes problems with social interaction and communication. Symptoms usually start before the third age and can cause delays or problems in many different skills that develop from infancy to adulthood. This neural disorder is little known from parents and teachers. The problem in the learning process depends even on the type of autism and the time of diagnosis. It is really difficult to diagnose these disorders due to the fact that they belong to the early years of childhood. Taking into consideration the information about the autistic children in Vlora, where there is a large number of autistic children I think that there will be a contribution related to their difficulties in the learning process and there will be collected more information on the causes of autism. There is no cure for autism, nor is there one single treatment for autism spectrum disorders. Anyway, there are ways to help minimize the symptoms of autism and to maximize learning, like Behaviour management therapy, Speech-language therapists, Physical therapists, Educational and/or school-based options. The researches will come up with real results in order to bring about more changes in the education policies and involving different projects of groups of interest.
\end{abstract}

Keywords: neural disorder, communication, socializing, learning difficulties.

\section{Introduction}

Autism spectrum disorder has become a global epidemic and is a major problem in all human society. Autism is a complex neurological disorder of unknown origin that causes problems with social interaction and communication and affects the child's ability to process information from his body or the surrounding environment. Symptoms usually begin before the age of three years and may cause delays or problems in many different skills to the growth and development of the child. Definition of DSM-IV describes that autism disorder consists of twelve possible symptoms in three areas of development .1)

These include socialization 2 ) significantly obvious in damaging non-verbal behavior, failure in peer relationships, inability to share the pleasure with others and the lack of socio-emotional reciprocity; communication 3) communication delay, without using gestures, hard to keep eye contact with others, lack of conversational ability, stereotypes and repeated language, lack of imaginary game; atypical activities and interests 4 ) limited interests, dysfunctional routines and rituals, as well as concern for objects with parts, which focuses on a part of the object, etc.

1. DSM IV. f. $57-78$

2. Miller. A. The Miller Method Autism, Play and Social Interaction p. 121-136

3. Dhamo.M. Çrregullimi dhe terapitë e të folurit f. 15-28, 199- 218

4. Autizmi i Fëmijës, Kriteret diagnostike sipas ICD-10 (OBSH1993)

To be diagnosed with autistic disorder, an individual must show at least six of the twelve symptoms, from which at least two are in the social sphere, together with one in any communication field and the field of atypical activities and interests. Various hypotheses have been cast if it is a lifelong developmental disability or rehabilitated with therapeutic interventions, pedagogical or clinical that affects social functioning and communication. Autism, which 10 years ago was considered a rare disorder where in 10.000 children only 1 was autistic, today is 1 in 150. From this disorder boys are more likely to be affected than girls (4 times more). From data of global statistics has been learned that in the U.S. 1 in every 100 newborn baby-boys will be diagnosed with autism before age 3 . In the UK the statistics are even worse, with 1 in every 58 children showing signs of autism 5). The same concern also shares the Albanian society where the phenomenon of this disorder is present everywhere with no racial, geographical, economic or intellectual preferences. So nowadays in Albania there has been no serious study to draw accurate statistics on the number of Albanian children affected by this disorder as it is done in developed countries. My preoccupation over the years for the recognition of 
psychology and neurology in function of the education of age up to 6 years and the worldwide alarm for autism has given me reason to make this mini-study on the phenomenon in question. The determination of the number of autistic children in the district of Vlora, the actual assessment of this disorder by the state, society, school and family, as well as clinical and pedagogical treatment are issues that need attention. Introducing the most sophisticated programs of treatment of autistic children as a necessity of time to help pediatricians, family and school is the immediate issue.

\section{Importance of the study}

Our findings will provide the impulse for a systematic research using such methods of treatment.

Why do I choose to treat this problem: It is a nervous disorder little known by doctors, and even less by parents, educators, teachers, etc. at a time when the number of autistic children is becoming a global concern. Since they show no physical disorder difficult their diagnosis becomes even more difficult until the age of 2 years.

\subsection{Social motive:}

The need to make society, family, parents and educators more sensitive to be part of the contribution in facilitating this nervous disorder.

\subsection{Psychological motive:}

The need to enter deeper into the study of neurological and psychological development of the age 0-6 years, especially brain development of the child at this stage as well as the discovery of factors that affect the disorder.

\subsection{Educational motive:}

The need for real integration of these children with normal children in order to gain somehow their independence and new skills.

Melillo. R. Disconnected Kids TheoryThe groundbreaking Brain Balance Program for children with autism, ADHD, Dyslexia, and Other Neurological Disorder. Introduction Different Symtoms, one Problem P. 3-7.

Genuine pedagogical motive and personal preferences: my preoccupation and commitment over the years to help in the pedagogical treatment of children with autism spectrum.

\section{Methodology}

Quantitative research, experimental type of children with autism spectrum disorders in the city of Vlora. At first, data on the number of autistic children in the city was collected (46, this figure is not final as not all the children with mental diagnosis were subject to this diagnosis) from the relevant institutions of social support and diagnosis, kindergartens and schools.

Time and subject of study, 2004 - 2011, with 19 children, 2-10 years old, who were divided into two groups, experimental group ( 9 children, 7 boys and 2 girls) and control group (10 children, 6 boys and 4 girls). Implementation steps of the experiment included literature review referring to the dissertations, researches and the latest world therapies as well as testing the presence of disorders, since the presence of initial unconstrained reflexes, in general checklist of hemispheres, etc. among the 19 children involved in the experiment.

\section{Experimental Group:}

- The first group: (2004-2007) three children, two boys and one girl

- The second group (2005-2008) three boys

- The third group (2007-2011) three children, two boys and one girl

\subsection{Control group:}

Ten children, six boys and four girls of different ages, who were not subject to any therapeutic intervention. 


\subsection{Control:}

Two checks were conducted to the two groups of children, before and after the experiment.

Firstly, a general control was made with the experimental children, the presence of initial reflexes was observed 6 ), assessment of the left and right hemisphere, under the checklist on the motor, sensory, emotional, behavioral and academic characteristics, immunity and autonomy 7). Then therapies with sensor-motor exercises were built in order to treat the brain through physical stimulation as therapeutic interfering based on the most recent global programs implemented 8 ) three times a week for one hour. (Dimitrios I. Zafeiriou, MD, PhD. Primitive Reflexes and Postural Reactions in The Neurodevelopmental Examination 7.Melillo.R. Disconnected Kids. The groundbreaking Brain Balance Program for children with autism , ADHD, Dyslexia, and Other Neurological Disorder. Master Hemisferic Checklist.2009. P. 82-93

8.Melillo.R. Disconnected Kids. The groundbreaking Brain Balance Program for children with autism , ADHD, Dyslexia, and Other Neurological Disorder. Sensory-Motor Exercises P. 149-183)

Food diet without gluten, casein and sugar was used 9) as well as parent training with the Miller method 10), the Melillo method applied at home11) etc.

With the control children the deficiency in the hemisphere was identified, and the relationship between reflex and distortion was determined (where possible) by making initial measurements in the: frequency of disturbed behavior, academic outcomes, self-report of the educator or teacher, self-report of the parent, interviews with them and their peers.

\subsection{Source of data for the number of autistic children:}

4.4

- Psychiatry Tiranë

- Psychiatry Vlorë

— Center "Fly for Life" Tirana

- National Center for Child Development and Rehabilitation. Combinat, Tirana

— Private Clinic "Rino" Tirana

- Social Service Office, Vlorë

- The Social Security Office, Vlorë

— Center "Sistina" Prishtina, Macedonia

4.5 The approximate number of autistic children until the year 2011

\begin{tabular}{|c|c|c|c|c|}
\hline Total & Boys & Girls & $\begin{array}{c}\text { Attendance of } \\
\text { kindergarten, school }\end{array}$ & $\begin{array}{c}\text { Receive economic } \\
\text { assistance }\end{array}$ \\
\hline 46 & 39 & 7 & 29 & 22 \\
\hline
\end{tabular}

4.6 Therapies

a. Miller method Developing the Capacities of Children on the Autism Spectrum

b. Melillo method. The groundbreaking Brain Balance Program for Children with Autism, ADHD, Dyslexia and other neurological disorder.

c. Support method. ABA

d. The establishment of clear rules and their repetition

e. Therapy of positive emotions

f. The VML Method-treating

g. Movement therapy

\section{The Successful Child}

With all the kids of the experiment the general checklist of the hemispheres was done by identifying a deficiency in the left or right brain, individual therapy after all had different symptoms and this is one of the problems. Criteria required for this work can not describe the progress of the checklist and of the individual treatment for all 9 children in the experiment. I present one of the treated children. 


\section{Research Goal and data collected}

The child that I will describe is G, actual age 8 years, without physical disorders (very beautiful). By collecting data from parents the pregnancy is considered as normal, with two intellectual parents and without any claim to genetic factors in inheritance or behavior disorder. His mother's pregnancy has gone as students in mathematics-physics associated with too much stress. She had no health problems. There has been no vaccine, drinking of alcohol, smoking or anything else during pregnancy. The child has started to move in uterus at the age of 3.5 months, slowly and not very often. $G$ was born with a weigh of $3.5 \mathrm{~kg}$ and normal. He has been only once breast-fed from his mother and he is fed only powder milk (PLAZMON). He has added weight normally. By the age of 2 months milk was associated with food. After 9 months he has stopped milk and continued only with food. He has drunk no more milk even in the kindergarten and still he doesn't like it. He has not moved on all fours or cat walking but is held in circular and has walked around 10 months.

At the age of 14-18 months has not touched many objects, is held at the baby-carriage or circular. Since 1 week after he was born he has been separated from parents and he has lived with his grandparents. His mother visited him only once a week or even more rarely. When she was one year old he started talking rare words like ball, sea, baby, but never said mum or dad. When his parents were leaving after visiting him he did not expressed any emotion. He didn't play with toys and do not integrate with other children. In some cases, he stayed only with adults especially with his grandparents.

At the age of 2 years he lived with his own parents and didn't say any words, neither them that he spoke earlier. At this age he stopped feeding immediately. He didn't use to be hunger and when he wanted to eat he yelled, cried, and become nervous, he threw angrily what he had in his hands, but without hurting himself. He didn't look people straight into their eyes, but above or sideways of their had. By the check-ups made to the pediatrician doctor because of not eating, he received counseling about nutrition and never was mentioned to him the word 'autistic' and the problem was never determined.

He started to eat only one kind of food like chips for a long time, then only rice etc. which was associated with loss of weight. He watched too much TV and made some annoying cries, a., a., a. many times. His sleep began to upset, he slept too late, and for 1-2 hours he woke up, quarreled etc. He didn't like to go somewhere or someone to come home, he did want anybody to touch or kiss him. Month after month he started to become addicted to any particular object which he hold at any time in his hands and made some stereotyped repetitive rotational movements, by closing one eye and approaching and removing the object. At the age of 2 years and a half he went in the kindergarten, where he had difficulty in socializing with friends, educators and the environment. He stood alone and liked to stay hidden in the corners. Later on, when he wanted something, he took you by the hand and lead to the object. The refusal was accompanied with strong crying and sometimes with self-injuries. Assistance has also been derived from video footage in cases of family birthday or holiday, where we can see his reactions with clear symptoms of an autistic disorder. From the visit made to the neuron-pediatrician doctor in the private clinic «Reno» in Tirana by the digital EEG \& the map of the brain at the age of 3.5 years he was diagnosed with infantile autism.

\section{Treatment Steps}

For the treatment of the disorder were used a set of methods integrated with each other. The method which holds more weight in the experiment was the Melillo method.

Test. The Brain Balancing program that I held was based on a technique called hemispheric integration therapy. First, there were a series of tests to assess symptoms and functional abilities which identified the hemisphere and the functions within the hemisphere that are out of balance. By the overall control of 200 of motor, sensory, emotional, behavioral and academic characteristics, immunity and autonomy of a delay of the right/ left brain of the Functional Block

Syndrome at the age of 3.5 years, he came up with 117 features and was classified in severe autism disorder 12).

12. Melillo.R.Disconnected Kids.The groundbreaking Brain Balance Program for children with autism ADHD, Dyslexia, and Other Neurological Disorder. Master Hemisferic Checklist. P. 92

The right hemisphere was weaker than the left hemisphere and with a disruption of activity.13)

\section{Exercises of this study}

This data was used for the implementation of the Brain Balancing Program, where a series of selected daily sensory, physical, and academic exercises 14) were planned which have a direct impact in the areas of deficiency. At first,these 
exercises were used separately to strengthen functional weaknesses and then was worked at the same time for the integration of large areas of the brain, especially the two hemispheres, in order to return them in synchronization. These exercises were applied three to four times a week for about an hour. The basis of hemispheric exercises was: Frequency was more important than intensity. Movements should be slow and focused on the activity. Physical exercise should be integrated with mental activities. The program was implemented after school and before dinner.Staying motivated and positive by leaving success, to the time. Important were breathing and muscle exercises, reactivation of sensory deficits, exercise of smell, sight.

Food diet. Brain Balancing program also includes a food program, food diets typical of autistic children, without gluten, casein and sugar. The diet was taken by «DIET LIST FOR CHILDREN WITH AUTISM» of Prof. Dr. Ahmet AYDIN (besahmet@yahoo.com), United States. Problems of diets are a cause of epidemic growth in children's neurological disorders. The feeding process was difficult because the child didn't eat and there was imposed to him any type of food by being fed by force even though this was accompanied by weeping. Specific advice was to be used white meat and with too much fat, as it had elements of hyperactivity and spent a lot of energy.

Sleep. Sleep had its disorders but by imposing and repeating every day the same activities was reached that the changes were immediate. It was never used any type of sedative or any drug for sleeping.

Environment The balance of the brain is also linked to the environment. Studies suggest strong connection with the problem 15).

Personal file with: History of pregnancy, birth, family, health, DNE child's learning development, case-record, and daily data on: verbal / non-verbal communication, socialization, sleeping, feeding, crying / self-injury, stereotyped movements, seeing / interests as well as all the daily therapeutic exercises etc.

Education At the age of 3.5 years he attended a private kindergarten with normal children, model «Montesori», 6 days a week, where the Melillo method was also implemented, elements from the Miller method etc. at the time of treatment.

The planning of different learning activities and the exit in the fresh air every day 16), play with as many movements as possible, running, etc 17). Repetition of daily activities, every day should start as the first day.Providing a place for playing to the physical environment of learning inside and outside the classroom as well as his favorite toys inside the classroom 18).

- To influence on the higher functions of the nervous system stimulant were used for stimulation and inhibition 19) during normal learning with other children. Different stimulants were used for stimulation and inhibition,alive animals and birds as: hedgehog, rabbit, turtle, horse, chicken, cat, etc. in order to create conditioned reflexes that affect nerve cell regeneration. The multiple movements and harassers for stimulation and inhibition were most of the learning process, as decisive factors in the realization of neural connections 20).

- Avoidance of watching television for a long time and the isolation in itself was facilitated by placing at his disposal at any time a guardian to attract his attention.

\section{Achievements until the current age of 8 years}

When $\mathrm{G}$ was introduced to the Brain Balance Program he had no voluntarily excrement, he couldn't do any self service, could not be dressed by himself, could not make eye contact, cut not spoke a word, could not be integrated into any play, did not share pleasure with others and lacked interest, showed no affection to relatives, even to his parents, hit himself and felt no pain, did not socialize etc. Our results from the Brain Balancing Program have been very fruitful. Many children with learning difficulties and autism spectrum disorders who were treated with this program progressed after three months. The results that were achieved were of academic performance, decrease of negative behaviors, substantial improvement in communication and social behavior. After 1 year, at the age of $4.5 \mathrm{G}$ spoke but continued to repeat ads or different sayings (echolalia). He rectified feeding in the kindergarten and at home. He removed pampers at the age of 5 years. He avoided stereotyped movements. Socialization was improved with everybody, children and adults. He was very intelligent in geography and in reading numbers, words and sentences. He kissed everyone that looked upset.

He asked: where is ? will they come ...? He asks for himself with the third person in some cases. He plays with friends. He sings and recites by keeping the order in the concerts of the kindergarten. A special characteristic was the intuition developed in many cases, for example once he said to his father, "Do not cry do not cry daddy". After a few days 
there was a heavy death in the family, or "teacher the glass is broken" and occurred after a while that the glass was broken.

With all the success that he achieved he didn't go to the first class at the age of 6 but at 7 .

In the early days of the school he had problems with socialization and irritation but later he managed to calm down. Accompanying difficulties during the first year of the school were writing and the usage of logic in different tasks of the learning process. He can read very well but he is not very good in retelling, he can add and subtract by using his fingers or other means, he goes to the shop, formulate clear questions and can associate the objects he buys with their proper features. For instance, "Mrs. could you give me a loaf of bread, please?" He pays but can not calculate the rest. Anyway he does not leave without taking the change. Now he expresses a strong affection toward his little sister by telling how much he loves her and by kissing her. He shows great care for her and all the other children.

\section{Conclusion}

The problem has a solution. Can not be judged as before when it was a lifelong disorder. Imbalance can be fixed by interfering in poor areas to strengthen them, reconnect, in order to return to normal rates.

Drugs are not a solution but they can help.

So far it has been worked with the strong side of the hemisphere and it is further strengthened by ignoring the malfunctioning side but this has deteriorated the disorder because of the increase of the imbalance. Signs of a left brain deficiency are usually more subtle than a problem of the right brain and can often go unnoticed until a child enters school.

Here is an easy way to remember the activities that are stored on each side of the brain. Conception of the body is like a car and of brain like a engine. The left brain is like the gas pedal, and the right brain is like the brakes.As a concrete conclusion for this case was made a general examination of 200 of motor, sensory, emotional, behavioral, and academic characteristics, immunity and autonomy of a delay of the right / left brain of the Functional Block Syndrome at the age of 6 years and a half, to see the evolution. He resulted with 58 features and was diagnosed with smooth disorder of autism. Relationship between hemispheres had obvious improvements.

Griseld communicates both verbally and non-verbally, interacts with friends, is no longer isolated in himself, performs independent actions, while statements of opinion, understanding and acting are not at the right level.

\section{Causes of Autism (I think)}

- Maternal stress during pregnancy.

- The non exact defining by the pediatrician at the moment of birth of the primitive reflexes to control brain development.

- The only 1 time of breast-feeding and the feeding for 9 months with "Plaznom" milk

- Affective reasons, not attachment with parents because of living only with his grandparents.

- Lack of socialization until the age of 2 years and a half, watching too much TV, not walking on all fours, he hasn't been much out and consequently his eyes have not seen a lot of things, and has not moved a lot to touch the things he wanted.

\section{The Reality in Vlora}

- There exist no private or state therapeutic center to provide therapy in this district.

- There exist no genuine professionals who provide therapy for autistic children but just PLM ordinary teachers.

- Do not take all economic support.

- Public institutions of mental health institutions do not offer qualitative service.

- There isn't any genuine study to specify the exact number of autistic children.

- Do not take all of them economic support and for those who receive it is just stimulating.

- Centers that provide services for such needs in Tirana are very expensive, and can not be afforded by the family. 


\section{Recommendations}

- I believe that the way to stop the growth of the epidemic in these neurological disorders that are threatening for the mental health of future generations is as many people as possible to get acquainted with these training techniques for correcting these disorders and the information that can help to prevent them.

- To establish centers with genuine specialists for the treatment of autistic children.

- To train parents of autistic children and teachers at home and abroad to facilitate disorder.

- Diagnosis and therapeutic treatment to be free of charge.

- The entire Albanian society to become more sensitive on the integration of autistic persons.

\section{References}

Autizmi i Fëmijës, Kriteret diagnostike sipas ICD-10 (OBSH1993)

ADHD, Dyslexia, and Other Neurological Disorder. Master Hemisferic Checklist.2009. P. 82-93

ADHD, Dyslexia, and Other Neurological Disorder. Neuroacademic assessment and home activities.184-255

ADHD, Dyslexia, and Other Neurological Disorder. Sensory-Motor Exercises P. 149-183

ADHD, Dyslexia, and Other Neurological Disorder. Master Hemisferic Checklist. P. 92

Autism Spectrum Disorders Through the Lifespan Digby Tantam - 2011

Britton. L. Montesori Play and Learn. 1992. P. 19- 24

DSM IV. f. $57-78$

Dieta for children with autism. Qendra "Sistina" Prishtinë, Maqedoni . besahmet@yahoo.com

ADHD, Dyslexia, and Other Neurological Disorder. Introduction Different Symtoms, one Problem P. 3-7.

Dimitrios I. Zafeiriou, MD, PhD. Primitive Reflexes and Postural Reactions in The Neurodevelopmental Examination p. 137-254

Dhamo.M. Çrregullimi dhe terapitë e të folurit. f. 15-28, 199- 218

Clara Hannanaford,PH.D. Smart moves. Movement.Basic for the brain , water and oxygen. P. 138- 156

Clara Hannanaford,PH.D. Smart moves. Movement. P. 96-107

Evidence-Based Practices and Treatments for Children with Autism Brian Reichow, Fred R. Volkmar, Peter Doehring - 2010

Miller. A. The Miller Method Autism, Play and Social Interactionv 2007 p. 121-136

Melillo.R. Disconnected Kids. The groundbreaking Brain Balance Program for children with autism, Miller. A with Chrétien. K. The Miller Method Developing the Capacities of Children on the Autism Spectrum. 2007. p. 17-33, 67-166

Miller.A Chrétien.K.The Miller Method_Developing the Capacities of Children on the Autism Spectrum. Edcation 191-222

J.Camber, M.Masson, LI.Dehen. Neurologjia.f.39-61

Kennedy, Diane M. The ADHD-Autism Connection. New York: Random House (Waterbrook Press), 2002

Psychology - 2007 Focus on autism research $\quad$ O. T. Ryaskin - 2004

Parents' education as autism therapists Michael Keenan, Ken P. Kerr, Karola Dillenburger - 200027

Tupe. E. Kur dhimbja premton dashuri. Të jetosh me një fëmijë autik p. 37-42

Terry.F. Pettijohn. Psikologjia nje hyrje koncize. 1996. f.46-47

The efficacy of peer-mediated interventions for promoting social Jie Zhang, Tennessee

Technological University- 2008

The perceived impact of the ABA and TEACCH Linda C. Seiford, Capella University. School of

Teaching children with autism Kathleen Ann Quill - 1995

Using aspects of the Treatment and Education Cheryl A. Banull, Loyola University Chicago - 2008 
